\title{
IDENTIFIKASI KEBUTUHAN FASILITAS PENUMPANG DI TERMINAL BERDASARKAN PERGERAKAN PENUMPANG
}

\author{
Tiafahmi Angestiwi \\ Program Studi Manajemen Aset Politeknik Negeri Bandung \\ Corresponding Author Email : tia.fahmi@polban.ac.id
}

\begin{abstract}
Terminal is one of the most important facility in transportation. As a start and finish site, terminal have to ensure to provide optimal services. Optimal services have to supported by adequate facilities, so that it can realize integrated transportation. The puropose of this study is to identify the facility needed for supporting passengers activity when start and finish their journey in terminal. The research methodology used is descriptive research with qualitative approach. Technique of collecting data used are observation and literature review. The result of the research, identify based on passenger movement from and to Leuwipanjang Terminal, needed any facility namely:1) pedestrian bridge and adequate pedestrian ways which is free from barrier 2) parking facility and drop zone area to avoid congestion in the area around the terminal.
\end{abstract}

Key word: Passenger Terminal, Passenger Terminal Facilities, Terminal Leuwipanjang

\begin{abstract}
ABSTRAK
Terminal merupakan salah satu sarana terpenting dalam transportasi. Sebagai tempat memulai dan mengakhiri perjalanan, terminal harus dipastikan dapat memberikan pelayanan secara optimal. Pelayanan yang optimal harus didukung oleh fasilitas yang memadai, sehingga dapat mewujudkan transportasi yang terintegrasi. Tujuan penelitian ini adalah untuk mengidentifikasi fasilitas yang dibutuhkan untuk mendukung aktivitas penumpang saat memulai dan mengakhir perjalanan di terminal. Metode penelitian yang digunakan adalah metode penelitian deskriptif dengan pendekatan kualitatif. Teknik pengumpulan data yang digunakan yaitu observasi dan literatur review. Hasil penelitian yang dilakukan, teridentifikasi bahwa berdasarkan pergerakan penumpang dari dan menuju terminal Leuwipanjang, dibutuhkan beberapa fasilitas yakni: 1) jembatan penyeberangan dan jalur pejalan kaki yang memadai serta bebas dari hambatan. Disamping itu dibutuhkan 2) fasilitas parkir dan area menurunkan penumpang untuk menghindari kemacetan di area sekitar terminal.
\end{abstract}

Kata kunci: Terminal Penumpang, Kebutuhan Fasilitas Terminal Penumpang, Terminal Leuwipanjang 


\section{PENDAHULUAN}

Semakin meningkatnya pertumbuhan penduduk mengakibatkan persebaran pemukiman hingga kawasan pinggiran kota Bandung. Alasan utama berpindahnya golongan menengah ke atas pada lokasi pinggiran kota yakni untuk menjauhi wilayah kota yang padat menuju kualitas lingkungan yang lebih baik. Berdasarkan Angestiwi, 2013 sebaran pusat kegiatan di Kota Bandung, membentuk kegiatan perkantoran, pertokoan, dan perdagangan yang sifatnya komersil. Jika dilihat dari sebaran penduduknya di zona 4 dan 5, pada Gambar 1, di zona tersebut masih terdapat area pemukiman kelas menengah keatas. Hal tersebut berdampak pada sebaran pemukiman ke luar area CBD (Central Business District).

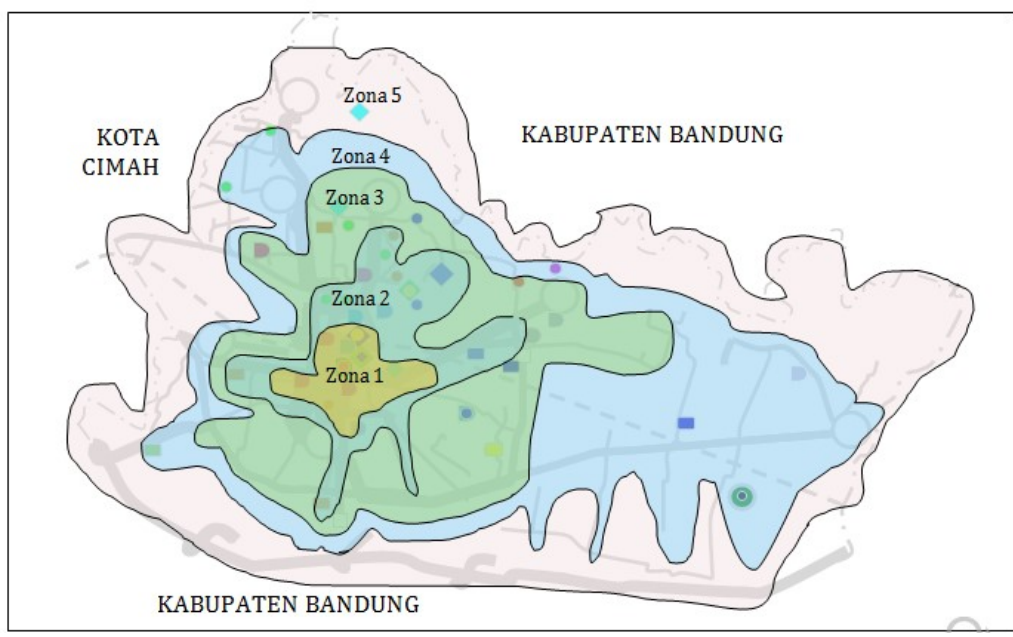

Gambar 1. Sebaran Pusat Kegiatan di Kota Bandung Sumber: Angestiwi, 2013

Hal tersebut berdampak pada peningkatan penggunaan kendaraan. Berdasarkan data dari Dinas Perhubungan Kota Bandung Tahun 2015, penggunaan kendaraan pribadi semakin meningkat sekitar 9.34\% tidak sebanding dengan penambahan jalan $1.29 \%$. Hal tersebut salah satunya sebagai dampak sebaran pemukiman yang menyebar ke pinggiran kota sehingga membutuhkan jarak tempuh yang semakin panjang menuju ke zona 1 sebagai kawasan komersil.

Permasalahan tersebut diperparah dengan fungsi jalan yang semakin beragam yakni lahan parkir, perdagangan, maupun terminal bayangan. Terminal bayangan merupakan simpul ilegal dimana terdapat aktivitas ngetem atau parkir sembarangan oleh Angkutan Umum Penumpang (AUP). Lokasi terminal yang berada di pinggir jalan seharusnya 
memudahkan seluruh pengguna, baik AUP maupun penumpang. Sehingga perlu diidentifikasi fasilitas-fasilitas yang dibutuhkan penumpang selama melakukan kegiatan di terminal. Tingkat kondisi dimana penumpang AUP belum memanfaatkan terminal sebagai tempat memulai, mengakhiri, bahkan berganti dari satu moda transportasi ke transportasi lainnya juga harus diperhatikan (Angestiwi, 2018).

Berdasarkan Teichholz (2004) komponen dalam mengelola fasilitas dibutuhkan kesinambungan antara orang, proses, dan tempat. Perlu diselaraskan antara apa yang dilakukan oleh pihak terkait dan dimana mereka melakukannya. Dalam hal ini fasilitas yang dibutuhkan diidentifikasi berdasarkan moda transportasi yang mereka gunakan dari satu terminal ke terminal lainnya.

Tujuan penelitian dilakukan untuk mengidentifikasi:

1. Fasilitas yang dibutuhkan di Terminal Leuwipanjang sebagai Terminal Asal

2. Fasilitas yang dibutuhkan di Terminal Cicaheum sebagai Terminal Tujuan

\section{METODOLOGI}

Metode penelitian yang digunakan yakni metode penelitian deskriptif. Metode penelitian deskriptif adalah metode penelitian yang dilakukan untuk mengetahui keberadaan variable mandiri, baik hanya pada sat variabel atau lebih (variabel yang berdiri sendiri atau variabel bebas) tanpa membuat perbandingan variabel itu sendiri dan mencari hubungan dengan variabel lain (Sugiyono, 2017). Metode penelitian deskriptif memaparkan kondisi saat dilakukannya penelitian yakni fasilitas-fasilitas yang dibutuhkan oleh penumpang berdasarkan rute layanan yang disediakan. Unit analisis yang digunakan dalam penelitian ini adalah terminal Leuwipanjang dan terminal Cicaheum sebagai tempat memulai dan mengakhiri perjalanan penumpang. Sedangkan unit responden yang digunakan yakni seluruh penumpang yang beraktivitas di kawasan terminal baik terminal Leuwipanjang maupun terminal Cicaheum. Jenis populasi yang digunakan yakni populasi infinit, yaitu anggota populasi yang memiliki kecenderungan bertambah maupun berkurang (Nazir, 2005). Teknik sampling yang digunakan

Teknik pengumpulan data yang digunakan yakni pengumpulan data primer dengan melakukan observasi perilaku penumpang saat akan menggunakan Angkutan Umum Penumpang (AUP) di terminal dan saat akan meninggalkan kawasan terminal. Data sekunder diperoleh dari UPTD Terminal untuk mengetahui fasilitas utama dan fasilitas pendukung yang tersedia di Terminal Leuwipanjang dan Terminal Cicaheum. 


\section{Terminal Penumpang}

Blow (2005) mendefinisikan terminal "as an area away from the general flow of road vehichles, which gives buses and coaches the freedom of movement to set down and pick up passengers in safety and comfort.Sedangkan dalam Permenhub No.40/2015 tentang standar pelayanan penyelenggaraan terminal penumpang angkutan jalan, terminal adalah pangkalan kendaran bermotor umum yang digunakan untuk mengatur kedatangan dan keberangkatan, menaikkan dan menurunkan orang dan atau barang serta perpindahan moda angkutan.

Dalam melayani berbagai kegiatan di perkotaan, terminal harus memenuhi standar pemenuhan berupa prasarana dan sarana penunjang. Menurut Adisasmita (2012) fasilitas yang dibutuhkan untuk sebuah terminal meliputi fasilitas utama dan fasilitas pendukung. Adapun fasilitas utama sebuah terminal antara lain:

1. Jalur pemberangkatan kendaraan umum

2. Jalur kedatangan kendaraan umum

3. Tempat parkir kendaraan umum selama menunggu keberangkatan, termasuk di dalamnya terdapat tempat tunggu dan tempat istirahat kendaraan umum

4. Bangunan kantor terminal

5. Tempat tunggu penumpang dan atau pengantar

6. Menara pengawas

7. Loket penjualan karcis

8. Rambu-rambu dan papan informasi tentang petunjuk jurusan, tarif, dan jadwal perjalanan

9. Pelataran parkir kendaraan pengantar dan atau taksi

Sedangkan fasilitas pendukung merupakan fasilitas yang dapat menambah kenyamanan bagi penumpang yaitu antara lain:

1) Kamar kecil atau toilet

2) Kios atau kantin

3) Mushola

4) Ruang pengobatan $P 3 K$

5) Ruang informasi dan pengaduan

6) Telpon umum dan atau wartel 
7) Taman

8) Tempat penitipan barang

\section{PEMBAHASAN}

Terminal Leuwipanjang merupakan terminal yang berlokasi di jalan arteri primer Kota Bandung. Lokasi tersebut mendukung Terminal Leuwipanjang dalam memberikan pelayanan ke kota-kota di sekitarnya. Adapun karakteristik perjalanan penumpang berdasarkan tujuan kegiatannya yakni untuk tujuan sekolah, bekerja, perdagangan, serta traveling.

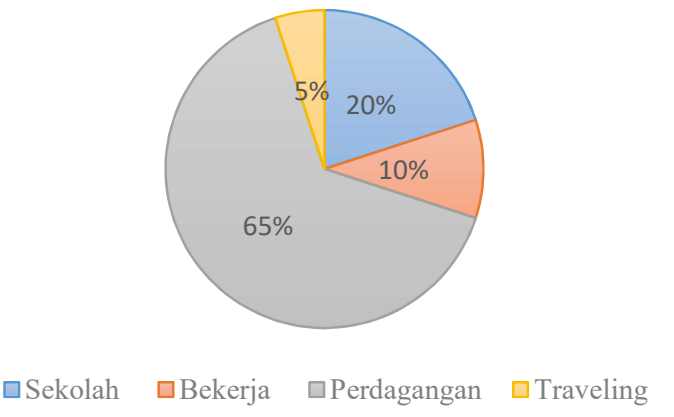

Gambar 2. Persentase Pengguna Terminal Berdasarkan Aktivitasnya

Berdasarkan gambar 2, dapat diamati bahwa mayoritas penumpang yang menggunakan terminal dengan tujuan perdangan yakni sekitar 65\%. Artinya jika terminal dapat memenuhi fasilitas yang dibutuhkan oleh penumpang secara langsung dapat meningkatkan perekonomian Kota Bandung. Berikut fasilitas-fasilitas yang teridentifikasi dibutuhkan di terminal Leuwipanjang dan Terminal Cicaheum.

1) Fasilitas yang Dibutuhkan di Terminal Leuwipanjang sebagai Terminal Asal

Memulai perjalanannya dari terminal Leuwipanjang, penumpang dikategorikan dengan beberapa aktivitas yakni aktivitas menuju terminal asal serta aktivitas turun dari AUP. Berdasarkan hasil pengumpulan data yang dilakukan selama satu dua hari yakni Sabtu dan Minggu dengan melakukan pengamatan penumpang teridentifikasi untuk menuju ke terminal Leuwipanjang, penumpang mencapai dengan berjalan kaki, menggunakan kendaraan pribadi serta menggunakan angkutan umum.

Bagi penumpang yang berjalan kaki mereka membutuhkan fasilitas pejalan kaki dan jembatan penyeberangan. Fasilitas pejalan kaki yang tersedia saat ini dapat dilihat pada Gambar 3. 


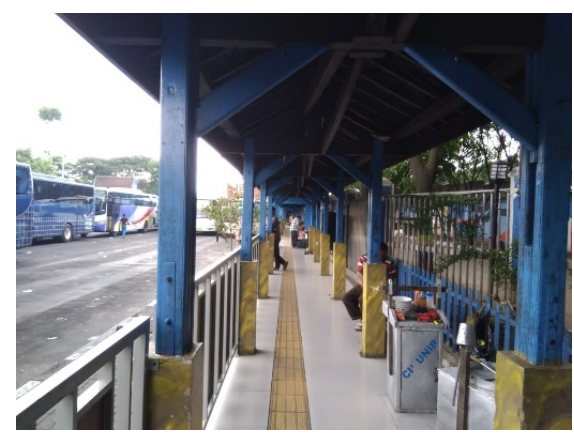

Gambar 3. Jalur Pejalan Kaki di Dalam Terminal Leuwipanjang

Berdasarkan Gambar 3 dapat dilihat jalur pejalan kaki yang berada di terminal Leuwipanjang sudah cukup nyaman namun belum bebas dari hambatan. Hal tersebut dapat dilihat dari pedagang kaki lima yang mangkal di sekitar jalur pejalan kaki.

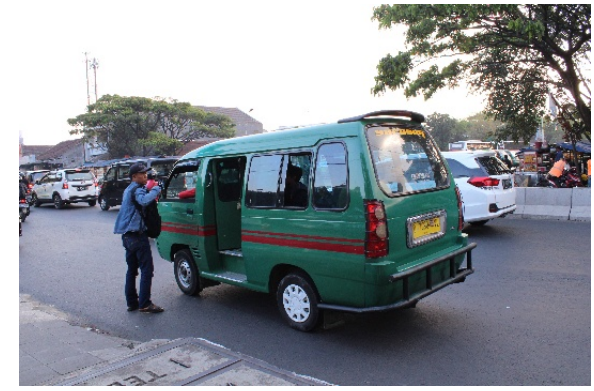

Gambar 4 Penumpang Menggunakan Kendaraan Umum

Pada Gambar 4 dapat dilihat penumpang yang akan memulai perjalanan di Terminal Leuwipanjang dengan menggunakan kendaraan umum. Penumpang membutuhkan penyeberangan jalan untuk menuju Terminal Leuwipanjang namun saat ini di kawasan Terminal Leuwipanjang belum tersedia fasilitas tersebut. Berdasarkan lokasi, Terminal Leuwipanjang berada di kawasan arteri primer yang melayani perjalanan antar kota antar provinsi. Berikut pada Gambar 5 dapat dilihat tempat parkir kendaran pribadi. 

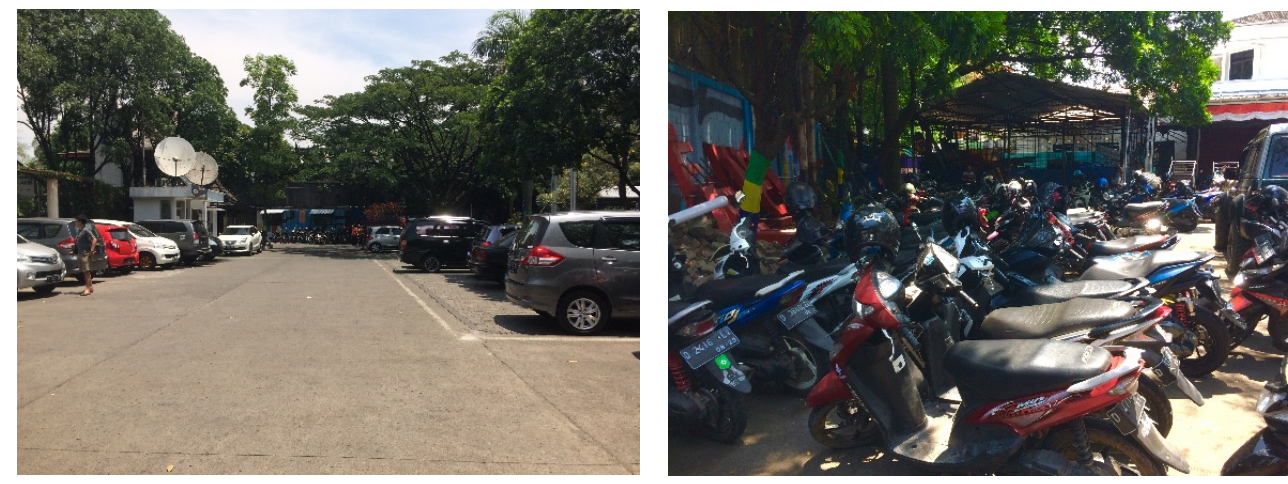

Gambar 5. Parkir Kendaraan Pribadi (Motor dan Mobil) di Terminal Leuwipanjang

Pada Gambar 6 dapat dilihat area menurunkan penumpang di kawasan Terminal Leuwipanjang. Saat ini area yang disediakan di terminal Leuwipanjang, areanya bersamaan dengan area pejalan kaki.
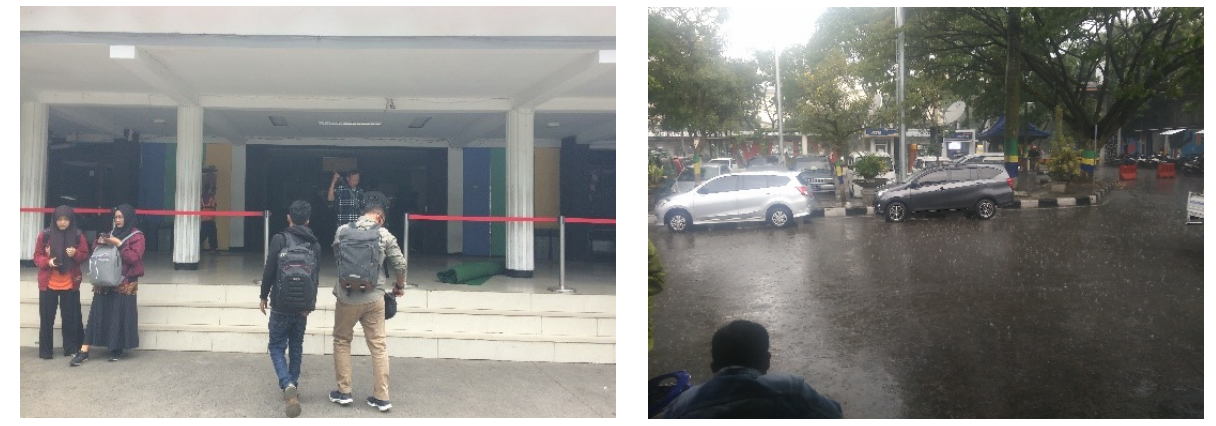

Gambar 6. Area Menurunkan Penumpang di Kawasan Terminal Leuwipanjang

Aktivitas lain yang dilakukan penumpang selama berada di terminal Leuwipanjang yakni turun dari AUP. Fasilitas yang dibutuhkan berupa toilet, ruang tunggu, area menaikkan penumpang, serta pintu keluar. Berdasarkan Angestiwi (2017) Terminal Leuwipanjang saat ini sudah menyediakan fasilitas toilet dan ruang tunggu dengan pelayanan yang memadai. Namun area menaikkan penumpang, belum memperhatikan tinggi platform sama dengan lantai bus. Terakhir fasilitas pintu keluar di terminal Leuwipanjang antara penumpang dengan AUP dibuat sama. Hal ini berdampak pada berkurangnya keselamatan bagi para pejalan kaki yang keluar masuk di terminal karena tidak ada batasan yang jelas antara pintu masuk bagi pejalan kaki dengan kendaraan (AUP) 


\section{2) Fasilitas yang dibutuhkan di Terminal Cicaheum sebagai Terminal Tujuan}

Berdasarkan Tabel 1 mengenai kebutuhan fasilitas di terminal penumpang dapat diamati bahwa aktivitas yang dilakukan penumpang di terminal tujuan yakni menunggu AUP dan keluar dari Terminal untuk menuju ke tempat tujuannya. Saat menunggu AUP, penumpang membutuhkan fasilitas ruang tunggu, toilet, mushola, charger facility, serta ketinggian jalan trotoar untuk naik ke AUP selanjutnya. Berdasarkan hasil observasi, diketahui bahwa di terminal Cicaheum sudah tersedia ruang tunggu, toilet, dan mushola. Sedangkan charger facility belum tersedia. Berdasarkan Peraturan Menteri Perhubungan RI No.40 Tahun 2015 tentang Standar Pelayanan Penyelenggaraan Terminal Penumpang Angkutan Jalan, terminal tipe B tidak diharuskan menyediakan charger facility. Namun untuk memberikan kenyamanan pada seluruh penumpang, sehingga perlu penyediaan fasilitas tersebut.

Tabel 1. Kebutuhan Fasilitas di Terminal Penumpang (Terminal Leuwipanjang menuju Terminal Cicaheum)

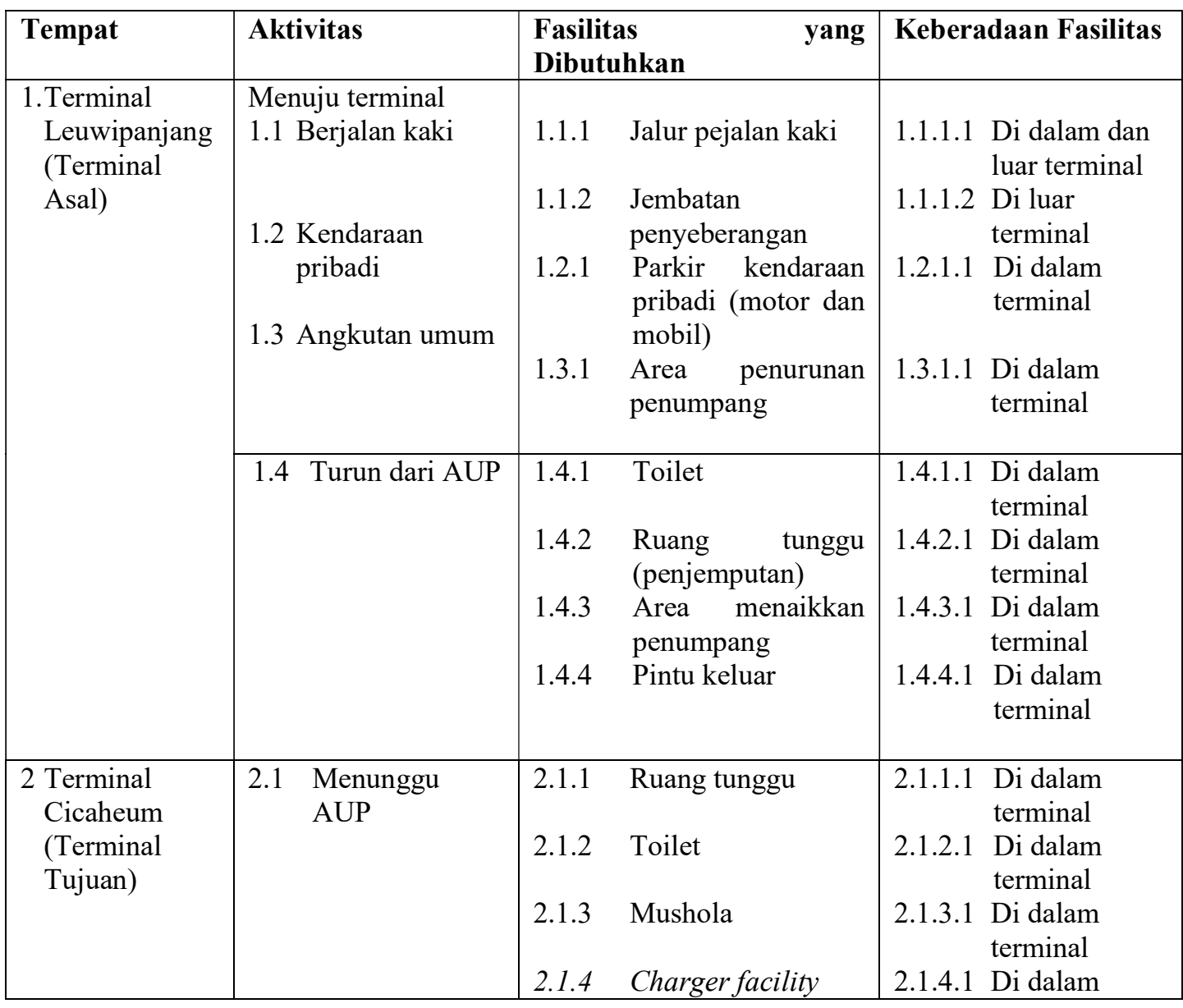


Vol 24 No 2 Tahun 2019

\begin{tabular}{|c|c|c|c|c|}
\hline \multirow[t]{3}{*}{ Tempat } & \multirow[t]{2}{*}{ Aktivitas } & \multicolumn{2}{|c|}{$\begin{array}{ll}\text { Fasilitas } & \text { yang } \\
\text { Dibutuhkan } & \\
\end{array}$} & Keberadaan Fasilitas \\
\hline & & 2.1 .5 & $\begin{array}{l}\text { Ketinggian jalan } \\
\text { untuk naik ke AUP }\end{array}$ & $\begin{array}{ll} & \text { terminal } \\
\text { 2.1.5.1 } & \begin{array}{l}\text { Di dalam } \\
\text { terminal }\end{array} \\
\end{array}$ \\
\hline & $\begin{array}{ll}\text { Keluar terminal } \\
2.2 \text { Jalan kaki } \\
2.3 \text { Angkutan } \\
\text { umum }\end{array}$ & $\begin{array}{l}2.2 .1 \\
2.2 .2 \\
2.3 .1\end{array}$ & $\begin{array}{l}\text { Jalur pejalan kaki } \\
\text { Jembatan } \\
\text { penyeberangan } \\
\text { Halte angkutan } \\
\text { umum }\end{array}$ & $\begin{aligned} 2.2 .1 .1 & \begin{array}{l}\text { Di dalam } \\
\text { terminal }\end{array} \\
2.2 .1 .2 & \begin{array}{l}\mathrm{Di} \\
\text { teminal }\end{array} \\
& \\
2.3 .1 .1 & \text { di Luar } \\
& \text { terminal }\end{aligned}$ \\
\hline
\end{tabular}

Aktivitas lain yang teridentifikasi di Terminal Cicaheum sebagai terminal tujuan yakni keluar dari Terminal. Berdasarkan aktivitas tersebut dibutuhkan fasilitas jalur pejalan kaki, jembatan penyeberangan, dan halte angkutan umum. Fasilitas bagi pejalan kaki di kawasan terminal Cicaheum belum tersedia, hal tersebut dapat dilihat pada Gambar 7. Penumpang yang akan naik ke AUP selanjutnya menggunakan bahu jalan yang digunakan AUP. Jalur pejalan kaki di sekitar kawasan tersebut penuh dengan penjual yang membuka kios nya hingga bahu jalan bagi pejalan kaki.

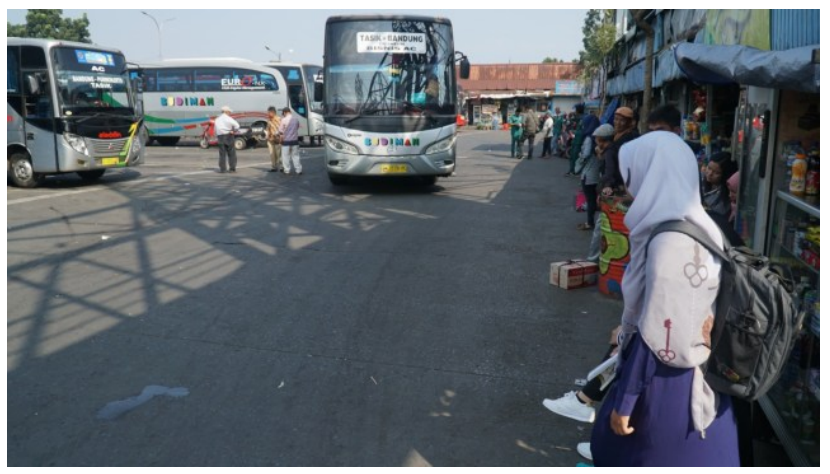

Gambar 7. Ketidaktersediaan Jalur Pejalan Kaki di Terminal Cicaheum

Pada Gambar 8, dapat dilihat jembatan penyeberangan yang sudah tersedia di Terminal Cicaheum. Terminal Cicaheum yang berada di kawasan perdagangan dan memiliki aktivitas yang tinggi, membutuhkan jembatan penyeberangan untuk mendukung keselamatan penggunanya. Namun tidak sedikit orang yang enggan memanfaatkan jembatan penyeberangan karena masih ada alternatif dengan menyeberang jalan. 


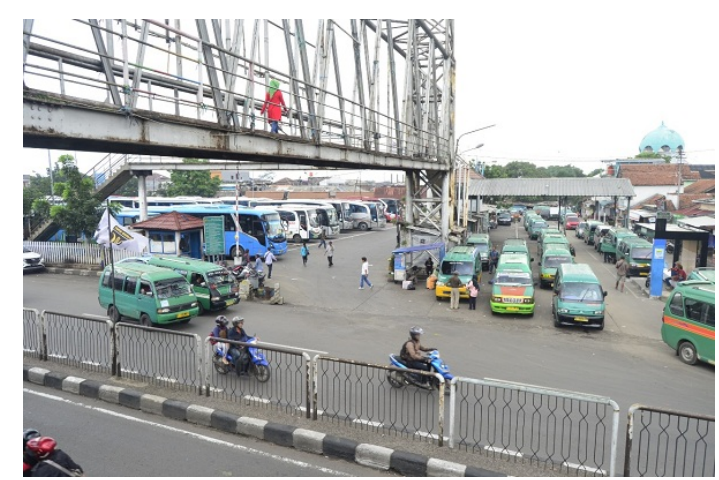

Gambar 8. Jembatan Penyeberangan di Terminal Cicaheum

\section{KESIMPULAN DAN SARAN}

\section{Kesimpulan}

Berdasarkan hasil analisis data, dapat ditarik kesimpulan sebagai berikut:

1. Fasilitas yang dibutuhkan di terminal Leuwipanjang sebagai Terminal Asal yakni bagi penumpang yang berjalan kaki, menggunakan kendaraan pribadi, maupun kendaraan umum. Penumpang yang tiba di terminal Leuwipanjang dengan berjalan kaki dibutuhkan jembatan penyeberangan dan jalur pejalan kaki yang memadai serta bebas hambatan. Disamping itu bagi penumpang yang menggunakan kendaraan pribadi dibutuhkan fasilitas parkir yang memberikan keamanan hingga penumpang tiba di terminal asal. Disamping itu bagi pengendara yang menggunakan kendaraan umum yakni ojeg online maupun angkutan umum, dibutuhkan area menurunkan penumpang yang mampu memastikan penumpang dalam keadaan aman dan tidak menimbulkan kemacetan di kawasan sekitarnya.

2. Fasilitas yang dibutuhkan di terminal Cicaheum berdasarkan aktivitas menunggu AUP yakni dibutuhkan ruang tunggu, toilet, mushola, charger facility, ketinggian jalan untuk naik ke AUP. Sedangkan untuk aktivitas keluar terminal dibutuhkan fasilitas bagi pejalan kaki dan pengguna AUP, yakni jalur pejalan kaki, jembatan penyeberangan, dan halte angkutan umum. Di terminal Cicaheum jembatan penyeberangan sudah tersedia, sehingga perlu mengoptimalkan penggunaan yang ada yakni mewujudkan 
jembatan penyeberangan yang nyaman dan bebas dari hambatan. Adapun hambatan tersebut berupa pedagang kaki lima yang berdagang secara permanen.

\section{Saran}

Berdasarkan kesimpulan tersebut, berikut saran yang direkomendasikan untuk UPT Terminal dan Dishub Kota Bandung:

1. Terminal Leuwipanjang berada di jalan arteri primer sehingga penting untuk menyediakan jembatan penyeberangan menuju terminal Leuwipanjang. Hal tersebut dapat mendukung kenyamanan penumpang serta mengurai kemacetan akibat adanya hambatan samping. Selain itu dibutuhkan area parkir yang sesuai dengan kapasitas penumpang terminal. Area penurunan penumpang di terminal Leuwipanjang sudah tersedia, namun perlu dioptimalkan sehingga tidak terjadi penumpukan aktivitas di zona yang sama .

2. Terminal Cicaheum sebagai terminal tipe B tidak diharuskan menyediakan charger facility namun untuk menunjang kebutuhkan dan kenyamanan para perumpang. Sedangkan jembatan penyeberangan yang sudah tersedia dapat dilakukan pemeliharaan sehingga dapat meningkatkan kenyamanan para penggunanya.

\section{DAFTAR PUSTAKA}

Adisasmitha, Sakti Adji. 2011. Transportasi dan Pengembangan Wilayah. Graha Ilmu

Angestiwi, T. (2018). Kajian Kondisi Fisik Terminal Leuwipanjang Berdasarkan Persepsi Penumpang. Jurnal Planologi, 15(1), 49-65.

Angestiwi, Tiafahmi. 2013. Kinerja Terminal Leuwipanjang Terhadap Pergerakan Kota Bandung. Bandung: Universitas Diponegoro

Angestiwi, Tiafahmi. 2017. Kajian Kondisi Fisik Terminal Penumpang Leuwipanjang Berdasarkan Persepsi Penumpang

Blow, C., 2005, Transport Terminals and Modal Interchages (Planning and Design), First Published, Architectural Press, Burlington MA

Teicholz, E., \& Techolz, E. 2001. Facility design and management handbook. New York, NY: McGraw-Hill.

Sugiyono. (2017). Metode Penelitian Kuantitatif, Kualitatif, dan R\&D. Bandung : Alfabeta, CV

Nazir, Moh. 2005. Metode Penelitian. Jakarta: Ghalia Indonesia

Menteri Perhubungan RI No.40 Tahun 2015 tentang Standar Pelayanan Penyelenggaraan Terminal Penumpang Angkutan Jalan 